\title{
Development of anti-ballistic board from ramie fiber
}

\begin{abstract}
A laminate of a composite was developed from Kevlar 29-ramie fiber reinforced by polyester resin for hard body armor. The focused given to the ballistic limit, maximum energy absorption, composite failure mode, lifetime rupture, target geometry and environmental effects. The results indicated that the maximum ballistic limit at impact speed is $623.97 \mathrm{~m} / \mathrm{s}$ for a $15-\mathrm{mm}$ target thickness and $837 \mathrm{~m} / \mathrm{s}$ for a target thickness of $25 \mathrm{~mm}$. The targets were improved in terms of the impact response with increasing relative humidity in the range of $50 \% \pm 20 \%$ but were relatively decreased in terms of resistance with increasing temperature.
\end{abstract}

Keyword: Anti-ballistic; Kevlar; Ramie fiber 